\title{
Reguladores de crecimiento en el desarrollo vegetativo de vitroplantas de Agave durangensis Gentry
}

\section{Growth regulators in the vegetative development of Agave durangensis Gentry vitroplants}

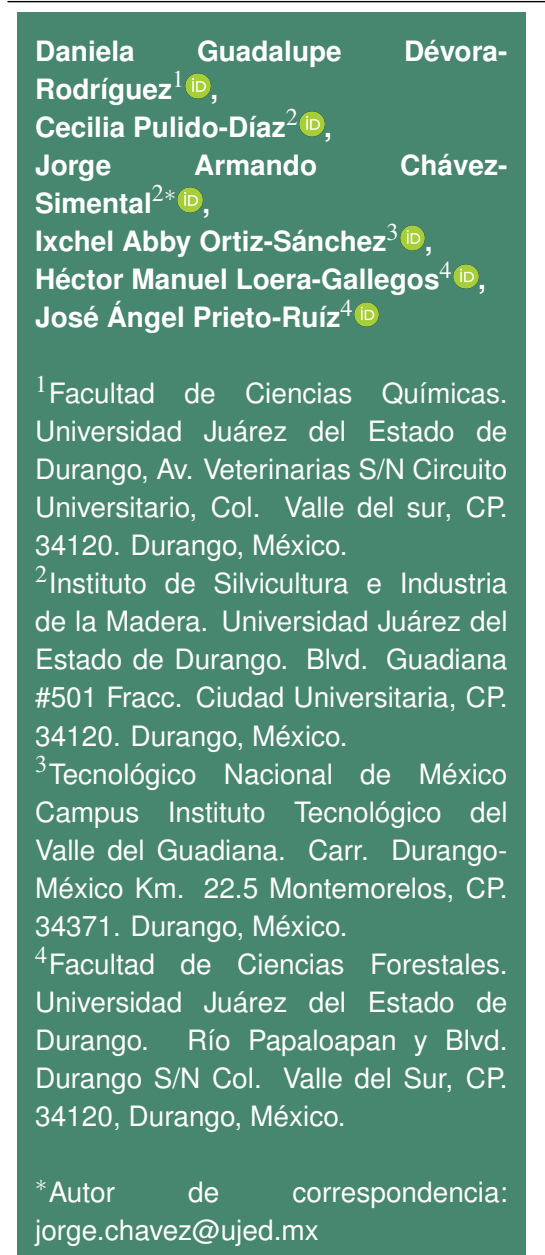

Nota científica

Recibida: 07 de septiembre 2020

Aceptada: 06 de abril 2021

Como citar: Dévora-Rodríguez DG, Pulido-Díaz C, Chávez-Simental JA, Ortiz-Sánchez IA, Loera-Gallegos HM, Prieto-Ruíz JA (2021) Reguladores de crecimiento en el desarrollo vegetativo de vitroplantas de Agave durangensis Gentry. Ecosistemas y Recursos Agropecuarios 8(1): e2720. DOI: $10.19136 /$ era.a8n1.2720
RESUMEN. Se estudió el efecto de citocininas y auxinas en la producción de brotes adventicios de Agave durangensis in vitro. La germinación se hizo en medio de cultivo Murashige y Skoog (MS) al 50\% de concentración, sin reguladores de crecimiento. La producción y desarrollo de brotes adventicios se realizó en medio de cultivo MS al 100\%, con citocininas (KIN y BAP) y ANA como auxina, evaluando diferentes concentraciones en 12 tratamientos. La concentración de $4.0 \mathrm{mg} \mathrm{L}^{-1}$ de BAP sin auxinas presentó mejores resultados en altura del explante, número de hojas por explante, número de brotes por explante y número de hojas por brote. La presencia de auxinas sólo favoreció la altura del brote en el tratamiento de $4.0 \mathrm{mg} \mathrm{L}^{-1}$ $\mathrm{KIN}$ y $0.4 \mathrm{mg} \mathrm{L}^{-1}$ ANA. Por lo anterior, resulta viable utilizar solo citocininas en medio de cultivo en la etapa de producción de brotes de $A$. durangensis.

Palabras clave: Agave durangensis Gentry, micropropagación vegetal, morfología de la planta, promotores de crecimiento, propagación in vitro.

ABSTRACT. The effect of cytokinins and auxins on the production of adventitious shoots of Agave durangensis in vitro was studied. Germination was done in Murashige and Skoog (MS) culture medium at 50\% concentration without growth regulators was used. The production and development of adventitious shoots was carried out in a 100\% MS culture medium with cytokinins (KIN and BAP) and ANA as auxin, evaluating different concentrations in 12 treatments. The concentration of $4.0 \mathrm{mg} \mathrm{L}^{-1}$ of BAP without auxins presented better results in explant height, number of leaves per explant, number of shoots per explant and number of leaves per shoot. The presence of auxins only favored the height of the sprout in the treatment of $4.0 \mathrm{mg} \mathrm{L}^{-1} \mathrm{KIN}$ and $0.4 \mathrm{mg} \mathrm{L}^{-1}$ ANA. Therefore, it is feasible to use only cytokinins on culture medium in the shoots production stage of $A$. durangensis.

Key words: Agave durangensis Gentry, plant micropropagation, plant morphology, growth promoters, in vitro propagation. 


\section{INTRODUCCIÓN}

El género Agave habita en América, con aproximadamente 200 especies registradas (García $2007)$, el $75 \%$ habita en México con alto porcentaje de endemismo, razón por la cual es el país con mayor riqueza y diversidad biológica de este género (García et al. 2010). El agave es un recurso natural con importancia ecológica y económica, ya que es formador y retenedor de suelo, sirve de refugio y alimento a una amplia gama de especies de fauna silvestre desde insectos hasta mamíferos, debido a la gran cantidad de polen y néctar que producen sus flores (Eguiarte y González 2007), y se aprovecha como materia prima para la elaboración de bebidas alcohólicas y fibras naturales (Martínez-Ramírez et al. 2014).

El Agave durangensis Gentry es originario de una región pequeña de la Sierra Madre Occidental ubicada en los estados de Durango y Zacatecas (Gónzalez y Nuñez 2015). En el estado de Durango se produce y consume mezcal por tradición, con un incremento en los últimos años, por lo que existe una creciente demanda de materia prima (González y Quintos 2006); no obstante, la oferta del mezcal duranguense a nivel local es suficiente en cantidad y calidad, por lo que aún es posible mantener el esquema tradicional de producción (Barraza et al. 2014). Pese a que $A$. durangensis puede ser producida a través de plantaciones, bajo condiciones de cultivo agrícola, en la región sureste del estado de Durango la materia prima (piña) se extrae de poblaciones silvestres (Hernández et al. 2017), lo que implica un riesgo potencial en la permanencia de estas poblaciones debido a que su aprovechamiento se realiza de forma empírica, sin considerar su capacidad de regeneración natural (Candia-Acosta et al. 2019). Ante este panorama, Loera et al. (2012) analizaron los factores ecológicos que influyen en el desarrollo de $A$. durangensis en la Sierra de Registrillo, Durango, Durango, como base en la determinación de la calidad de sitio para estimar el potencial productivo del Agave, con la finalidad de contribuir al enriquecimiento de los programas de manejo y productividad sustentable del recurso; encontrando que la densidad de población varía en función de la pendiente, la exposición y la textura del suelo. Mientras que, Loera et al. (2018) señalan que para la explotación sustentable de poblaciones silvestres, es necesario implementar estrategias de manejo, donde uno de los ejes primordiales es producir planta de calidad capaz de adaptarse a las condiciones donde se establecerán.

Una alternativa prometedora para la producción de plantas y para la resolución de estos problemas, es la micropropagación (Domínguez et al. 2008a), la cual permite la propagación masiva y la regeneración de plantas en un corto período, bajo condiciones controladas de luz artificial utilizando medio de cultivo orgánico (González et al. 2020) e inorgánico mejorado con sales minerales, vitaminas y hormonas sintéticas (Puente-Garza et al. 2017, Salazar-Mercado y Vega-Contreras 2017), ayudando a mejorar y mantener su diversidad. Sobre lo mismo Ying et al. (2011) señalan la importancia de la interacción de las auxinas-citocininas en el desarrollo de meristemos, ya que es posible obtener resultados satisfactorios en la generación de nuevos órganos vegetales, dependiendo de la concentración utilizada para cada etapa vegetativa. Al respecto, se reportan trabajos de investigación de cultivo in vitro para la propagación de Agave de diversas especies, entre los que destacan: $A$. inaequidens (Aureoles-Rodríguez et al. 2008), A. cupreata, A. karwinskii, A. obscura, A. potatorum y $A$. difformis (Domínguez et al. 2008b), A. tequilana (Valenzuela et al. 2006), A. salmiana (Silos et al. 2007, Puente-Garza et al. 2017), A. durangensis (Ramírez et al. 2008, González y Núñez 2015, González et al. 2020, Chávez-Ortiz et al. 2021), A. marmorata (Aguilar y Rodríguez 2018) y A. americana (Miguel et al. 2014). Por lo anterior el objetivo del presente trabajo fue evaluar el efecto de citocininas y auxinas en diferentes concentraciones en la etapa de producción de brotes adventicios in vitro de Agave durangensis Gentry.

\section{MATERIALES Y MÉTODOS}

El estudio se realizó en el laboratorio del área de producción de planta del Instituto de Silvicultura e Industria de la Madera de la Universidad Juárez 
del Estado de Durango (ISIMA-UJED), ubicado en las coordenadas $24^{\circ} 00^{\prime} 42.25^{\prime \prime} \mathrm{LN}$ y $104^{\circ} 41^{\prime} 23.28^{\prime \prime} \mathrm{LO}$, a una altitud de $1906 \mathrm{~m}$ en la ciudad de Durango, Durango, México.

Se utilizaron semillas de plantas adultas de A. durangensis del Jardín Botánico del ISIMA, ubicado en el mismo sitio del área de estudio. Previo a la utilización de las semillas, se mantuvieron en refrigeración durante 14 días a $4{ }^{\circ} \mathrm{C}$.

La asepsia se realizó sumergiendo la semilla en diferentes soluciones y tiempos de inmersión con agitación constante; para ello se colocaron las semillas en $35 \mathrm{~mL}$ de agua destilada con tween 20 (9.5:0.5) durante 10 minutos. Luego en $35 \mathrm{~mL}$ de etanol al $70 \%$ durante dos minutos, se realizó un enjuague con $30 \mathrm{~mL}$ de agua destilada después de cada solución durante un minuto; por último, se sumergieron en $35 \mathrm{~mL}$ de agua destilada con cloro (9:1) durante 25 minutos y se realizó un triple enjuague con $30 \mathrm{~mL}$ de agua destilada estéril durante un minuto.

Para la germinación, la semilla desinfectada se puso en medio de cultivo Murashige y Skoog 1962 (MS) concentrado al $50 \%$ de las sales originales, $\mathrm{pH}$ de 5.7 y $7 \mathrm{~g}$ de agar como agente gelificante, sin reguladores de crecimiento. La siembra se realizó en la campana de flujo laminar bajo condiciones controladas, colocando una semilla de $A$. durangensis en cada frasco de vidrio de $250 \mathrm{~mL}$ de capacidad con 20 $\mathrm{mL}$ de medio de cultivo. Los frascos con la siembra se colocaron en una cámara de germinación con temperatura de $22{ }^{\circ} \mathrm{C} \pm 2$ en condiciones de oscuridad total hasta que se observó la aparición del coleóptilo. Después se trasladaron a una cámara de crecimiento, con fotoperiodo inducido de 16/8 horas luz/oscuridad, a temperatura promedio de $25{ }^{\circ} \mathrm{C}$ y humedad relativa de $80 \%$, durante 50 días.

Para la producción de brotes adventicios se establecieron 12 tratamientos en medio de cultivo MS al $100 \%$ de sus sales minerales, enriquecido con reguladores de crecimiento en diferentes concentraciones bajo un diseño completamente al azar con 10 repeticiones (Tabla 1 ). Para multiplicar los brotes se retiró la raíz de las plántulas, mediante un corte transversal con un bisturí colocando la parte foliar en un nuevo frasco de medio de cultivo con las concentraciones propuestas de reguladores de crecimiento. Se realizaron mediciones cada 15 días hasta los 75 días después del establecimiento. Las variables evaluadas fueron: altura del explante $(\mathrm{cm})$, número de hojas por explante y número de brotes por explante, altura del brote $(\mathrm{cm})$ y número de hojas por brote. Los datos obtenidos se analizaron con el paquete estadístico InfoStat y la comparación de medias se realizó mediante la prueba de Diferencia Mínima Significativa (DMS) Fisher $(p \leq 0.05)$.

Tabla 1. Tratamientos para evaluar los reguladores de crecimiento y concentraciones en la etapa de producción de brotes de Agave durangensis.

\begin{tabular}{lc}
\hline $\begin{array}{l}\text { Tratamiento } \\
(\mathrm{T})\end{array}$ & $\begin{array}{c}\text { Concentración de regulador de crecimiento } \\
\left(\mathrm{mg} \mathrm{L}^{-1}\right)\end{array}$ \\
\hline 1 & $2.0 \mathrm{KIN}$ \\
2 & $3.0 \mathrm{KIN}$ \\
3 & $4.0 \mathrm{KIN}$ \\
4 & $2.0 \mathrm{BAP}$ \\
5 & $3.0 \mathrm{BAP}$ \\
6 & $4.0 \mathrm{BAP}$ \\
7 & $2.0 \mathrm{KIN}: 0.2 \mathrm{ANA}$ \\
8 & $3.0 \mathrm{KIN}: 0.3 \mathrm{ANA}$ \\
9 & $4.0 \mathrm{KIN}: 0.4 \mathrm{ANA}$ \\
10 & $2.0 \mathrm{BAP}: 0.2 \mathrm{ANA}$ \\
11 & $3.0 \mathrm{BAP}: 0.3$ ANA \\
12 & $4.0 \mathrm{BAP}: 0.4$ ANA \\
\hline Dónde: KIN: Kinetina, BAP: Bencilaminopurina, ANA: Ácido \\
naftalenacético.
\end{tabular}

\section{RESULTADOS Y DISCUSIÓN}

Se observaron diferencias significativas ( $p \leq$ $0.05)$ entre tratamientos en la variable altura del explante, la mayor altura se presentó en los tratamientos adicionados solo con citocininas al medio de cultivo (T1 al T6), la cual fluctuó entre 6.11 y $6.94 \mathrm{~cm}$, resultando con igualdad estadística entre ellos con respecto a los tratamientos donde se utilizó la mezcla de citocininas y auxinas 10:1 (Tabla 2). También se observó un efecto de inhibición o retardo del crecimiento vertical del explante con la concentración media y alta de KIN (3 y $4 \mathrm{mg} \mathrm{L}^{-1}$ ), pero con dosis baja ( $2 \mathrm{mg} \mathrm{L}^{-1}$ de $\mathrm{KIN}$ ) que fue igual al resultado de la hormona BAP en concentración alta y baja. Al respecto, González y Núñez (2015), mencionan que la altura de $A$. durangensis, se favorece con la 
Tabla 2. Efecto de los reguladores de crecimiento con diferente concentración en la morfología del explante de $A$. durangensis en condiciones in vitro.

\begin{tabular}{lllll}
\hline $\begin{array}{l}\text { Tratamiento } \\
(\mathrm{T})\end{array}$ & $\begin{array}{c}\text { Descripción } \\
\left(\mathrm{mg} \mathrm{L}^{-1}\right)\end{array}$ & $\begin{array}{l}\text { Altura del } \\
\text { explante }\end{array}$ & $\begin{array}{l}\text { No. de hojas } \\
\text { por explante }\end{array}$ & $\begin{array}{l}\text { Altura del } \\
\text { brote }\end{array}$ \\
\hline 1 & $2.0 \mathrm{KIN}$ & $6.85^{a}$ & $3.13^{b c d}$ & $1.61^{e}$ \\
2 & $3.0 \mathrm{KIN}$ & $6.24^{a b c}$ & $3.25^{b c d}$ & $1.63^{e}$ \\
3 & $4.0 \mathrm{KIN}$ & $6.11^{a b c}$ & $3.63^{a b c}$ & $1.63^{e}$ \\
4 & $2.0 \mathrm{BAP}$ & $6.93^{a}$ & $4.00^{a b}$ & $1.23^{e}$ \\
5 & $3.0 \mathrm{BAP}$ & $6.30^{a b}$ & $3.25^{b c d}$ & $2.31^{d e}$ \\
6 & $4.0 \mathrm{BAP}$ & $6.94^{a}$ & $4.50^{a}$ & $3.21^{c d}$ \\
7 & $2.0 \mathrm{KIN}: 0.2 \mathrm{ANA}$ & $4.85^{d}$ & $3.63^{a b c}$ & $4.76^{a}$ \\
8 & 3.0 KIN : 0.3 ANA & $4.85^{d}$ & $3.63^{a b c}$ & $4.50^{a b}$ \\
9 & $4.0 \mathrm{KIN}: 0.4 \mathrm{ANA}$ & $5.59^{b c d}$ & $3.25^{b c d}$ & $4.83^{a}$ \\
10 & 2.0 BAP : 0.2 ANA & $5.25^{d}$ & $3.38^{b c d}$ & $3.66^{a b c}$ \\
11 & 3.0 BAP : 0.3 ANA & $5.18^{d}$ & $2.50^{d}$ & $3.56^{a b c d}$ \\
12 & 4.0 BAP : 0.4 ANA & $5.43^{c d}$ & $2.75^{c d}$ & $3.28^{b c d}$ \\
\hline Medias con letras diferentes en la misma columna indican diferencia significativa \\
entre tratamientos DMS Fisher (p $\leq 0.05$ ).
\end{tabular}

mezcla de KIN:IBA en concentración 1:100. De igual forma, pero en $A$. inaequidens, Aureoles-Rodríguez et al. (2008) encontraron los mayores valores en la misma variable con $3.0 \mathrm{mg} \mathrm{L}^{-1}$ de $\mathrm{KIN}$, con una altura promedio de $4.34 \mathrm{~cm}$. Siendo en el presente trabajo los resultados superiores a los mostrados en la investigación anteriormente citada, con una una especie diferente.

Para el número de hojas por explante, se encontraron diferencias estadísticas entre tratamientos $(p \leq 0.05)$ (Tabla 2). Los T3, 4, 6, 7 y 8 tuvieron la mejor respuesta a la producción de hojas, con igualdad estadística entre ellos (Tabla 2). Al respecto, Aureoles-Rodríguez et al. (2008) observaron que la mayor cantidad de hojas en $A$. inaequidens se presentó con la adición de $3.0 \mathrm{mg} \mathrm{L}^{-1}$ de BA en el medio de cultivo, con 5.86 hojas en promedio, y $10.0 \mathrm{mg}$ $\mathrm{L}^{-1}$ de $\mathrm{KIN}$ tuvieron en promedio 4.71 hojas por explante. Este último valor es similar a lo obtenido en el presente trabajo en el tratamiento $\mathrm{T} 6\left(4 \mathrm{mg} \mathrm{L}^{-1}\right.$ de BAP) con media de 4.5 hojas. En contraparte, los tratamientos adicionados con KIN 2.0 y $3.0 \mathrm{mg} \mathrm{L}^{-1}$ (T1 y T2), tuvieron disminución en el número de hojas, con presencia de fenoles en respuesta fisiológica al corte del tejido vegetal entre los 30 y 45 días. El T1 presentó buena respuesta en la altura del explante, por lo que se esperaba el mismo efecto en la generación de hojas; sin embargo, al presentar necrosis en el tejido vegetal provocó que las hojas se desprendieran del explante, al igual que en el T2.
Respecto a esta situación, Gónzalez y Nuñez (2015) reportan un efecto similar con $A$. durangensis, encontrando que la mezcla de KIN:IBA en igual concentración $\left(0.1 \mathrm{mg} \mathrm{L}^{-1}\right)$ presentó necrosis en las puntas. Esto se puede deber a factores como la acción metabólica de los reguladores de crecimiento en la planta, al exceso de humedad que se forma en la atmósfera del frasco o bien, al requerimiento de más oxígeno por parte de la planta.

Por otra parte, el análisis estadístico no reveló diferencias significativas entre tratamientos $(p \leq$ 0.05 ) en la generación de brotes, manteniendo una variación entre 0.9 y 1.4 brotes por explante a los 75 días (Figura 1). En los T8 al 12, con citocininas y auxinas (10:1), la aparición de brotes se observó entre el día 15 y el 30 , a diferencia de los tratamiento T1 al T5 donde los brotes aparecieron entre el día 30 y 45 (Figura 2). Los tratamientos T6 y T10 destacaron por presentar mayor número de brotes, con media de 1.4 brotes, pero en el T6 al igual que en el T7, la aparición de brotes fue más tardía, ya que inició entre los días 45 y 60 . De acuerdo con lo recomendado por González y Núñez (2015), para A. durangensis la mezcla de $3 \mathrm{mg} \mathrm{L}^{-1}$ de $\mathrm{KIN}$ con $0.3 \mathrm{mg} \mathrm{L}^{-1}$ de IBA puede generar mayor número de brotes, con una media de 4.33. Por otra parte, Ramírez et al. (2008) reportaron que la mejor respuesta en producción de brotes para esta misma especie se obtiene con 4.44 $\mu \mathrm{M}$ BA/0.049 $\mu \mathrm{M}$ IBA, equivalentes a $9.91 \mathrm{mg} \mathrm{L}^{-1} \mathrm{y}$ $0.009 \mathrm{mg} \mathrm{L}^{-1}$ con promedio de 5.96 brotes axilares 


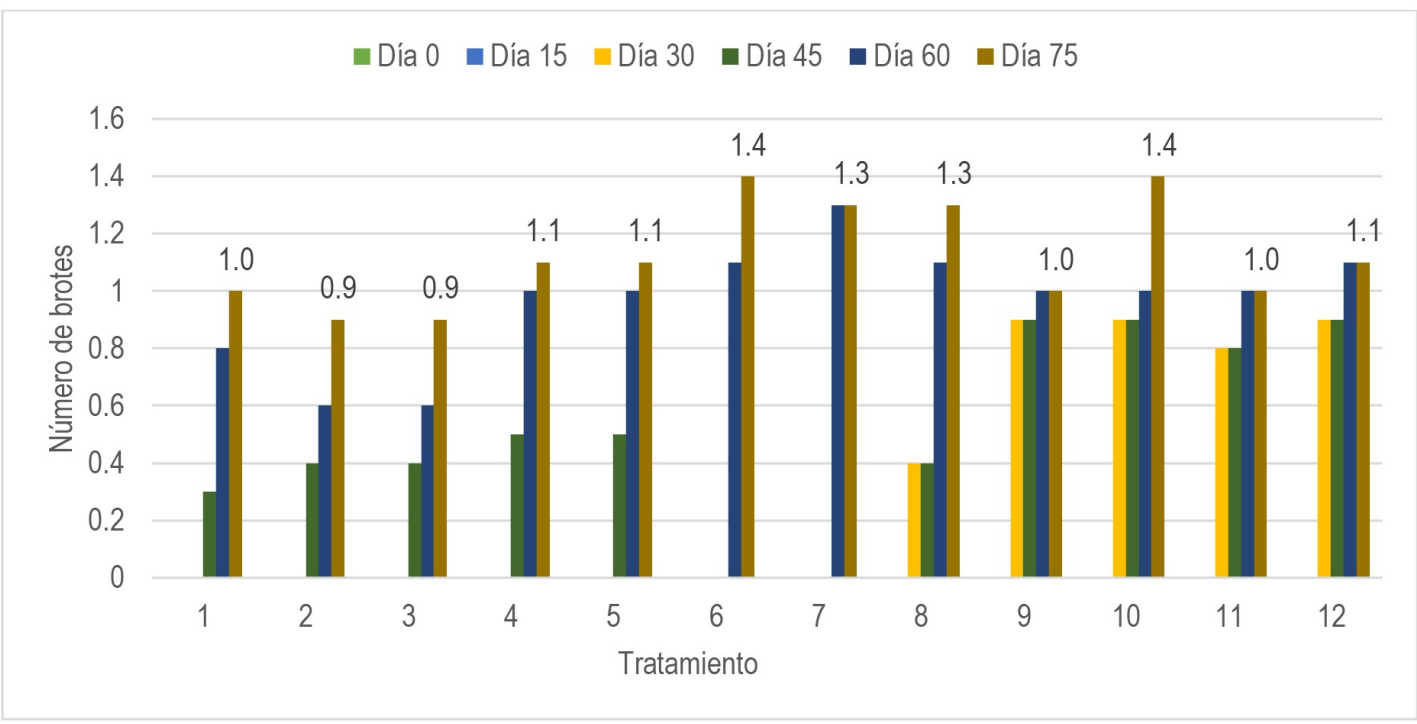

Figura 1. Promedio de brotes generados por explante de A. durangensis, sometido a distintas concentraciones de KIN, BAP y ANA in vitro.

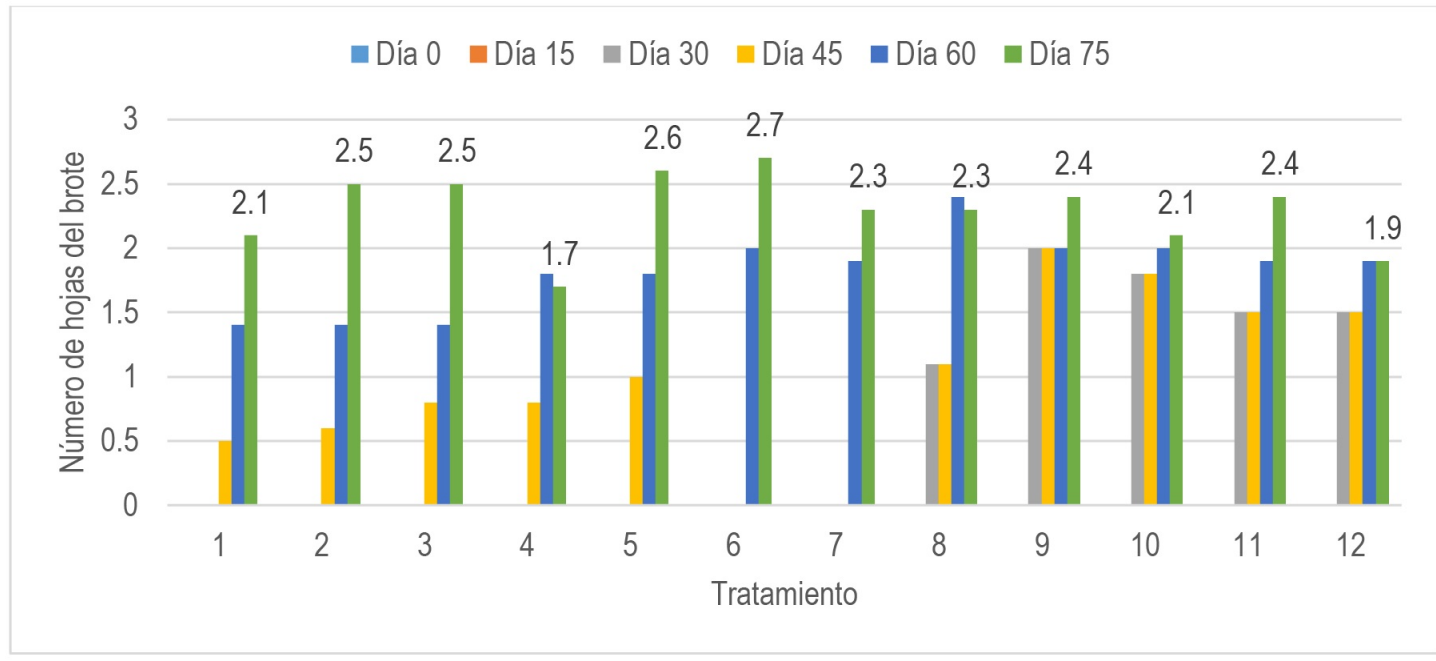

Figura 2. Número de hojas del brote primario de A. durangensis.

por explante a los 60 días. En el presente experimento no se obtuvieron valores como los reportados por los autores citados, pero el T6 $\left(4.0 \mathrm{mg} \mathrm{L}^{-1}\right.$ de $\mathrm{BAP})$ y el T9 (4.0 KIN + 0.4 ANA) produjeron igual número de brotes, siendo en el T6 la aparición de brotes de forma más gradual y homogénea, lo que podría indicar que la presencia de auxinas como ANA tiene un efecto en la generación de brotes adventicios, lo que coincide con lo reportado por Miguel et al. (2014). La característica que comparten estos tratamientos es que ambos corresponden a la concentración alta de citocininas, lo que coincide con lo mencionado por Aguilar y Rodríguez (2018), quienes argumentan que altas concentraciones de citocininas con respecto a las auxinas, promueven la formación de callos derivando la formación de brotes poco diferenciados. En tanto que Miguel et al. (2014), mencionan que el efecto de las interacciones sobre la for- 
mación de brotes podría deberse a que el proceso de organogénesis consume energía proporcionada por los carbohidratos, pese a que la citocinina desempeña un papel importante para inducir la formación de nuevos brotes. Con otra alternativa de micropropagación, Chávez-Ortiz et al. (2021) observaron que es posible generar brotes de $A$. guiengola utilizando solamente $1 \mathrm{mg} \mathrm{L}^{-1}$ de BAP sin auxinas en un sistema de biorreactores de inmersión temporal al generar un promedio de 3.7 brotes por explante.

Para la altura del brote, el análisis estadístico mostró diferencias significativas ( $p \leq 0.05)$, sobresaliendo los tratamientos del T7 al T11 con valores estadísticos similares, con alturas entre 3.56 y 4.83 $\mathrm{cm}$. Por lo que los tratamientos adicionados solo con citocininas ( $\mathrm{T} 1 \mathrm{al} \mathrm{T} 6)$ presentaron menor altura, con valores entre 1.23 y $3.21 \mathrm{~cm}$ (Tabla 2). A diferencia de la altura del explante con mezcla de citocininas y auxinas (10:1) que tuvieron los mayores resultados, el efecto de esta mezcla en sus tres concentraciones tuvieron los mayores resultados en la altura del brote. Al respecto, Aguilar y Rodríguez (2018) reportan efecto significativo en la longitud de brote de $A$. marmorata al incrementar la concentración de auxinas (AIA) sin la adición de citocininas. Mientras que, Miguel et al. (2014) mencionan que al incrementar la dosis de BAP, en cantidades mayores a $6 \mathrm{mg} \mathrm{L}^{-1}$, no ocurre la formación de cantidades adicionales de brotes y los que se lograron obtener fueron cada vez más pequeños. Este mismo efecto se observó en el presente experimento desde la concentración $2.0 \mathrm{mg} \mathrm{L}^{-1}$ de BAP, con mayores efectos en los tratamientos que sólo contenían citocininas.

La aparición de hojas se presentó a partir del día 45 en la mayoría de los tratamientos. Al igual que en la cantidad de hojas por explante, en esta variable destacó el T6 (4.0 $\mathrm{mg} \mathrm{L}^{-1}$ BAP) con 2.7 hojas por brote, sin embargo, aparecieron a partir del día 60 (Figura 2). En los tratamientos del T8 al T12, la aparición de hojas se mostró de forma gradual entre los días 15 y 30 , sobresaliendo el T9 y T11 con $4.0 \mathrm{mg}$ $\mathrm{L}^{-1} \mathrm{KIN}: 0.4 \mathrm{mg} \mathrm{L}^{-1}$ ANA y $3.0 \mathrm{mg} \mathrm{L}^{-1}$ BAP: $0.3 \mathrm{mg}$ $\mathrm{L}^{-1}$ ANA respectivamente (Figura 2). Lo anterior se contrapone con lo reportado por Aureoles-Rodríguez et al. (2008), quienes reportaron que la adición de $3.0 \mathrm{mg} \mathrm{L}^{-1}$ de BAP al medio de cultivo, incrementó la altura de los brotes y la formación de nuevas hojas en $A$. inaequidens. Sin embargo, el hacer la comparación entre diferentes especies, puede ser la razón de los resultados reportados, dado que para A. durangensis la presencia de auxinas favoreció el número de hojas por brote y su aparición gradual durante el proceso.

La adición de reguladores de crecimiento al medio de cultivo en la etapa de producción de brotes adventicios de $A$. durangensis, mostró un efecto significativo en las variables evaluadas. La presencia de auxinas presenta un efecto retardante $o$ inhibidor en la mayoría de las variables morfológicas evaluadas. La adición de $4.0 \mathrm{mg} \mathrm{L}^{-1}$ de BAP (T6) al medio de cultivo, sobresalió en cuatro de cinco variables evaluadas y el efecto de la mezcla de KIN:ANA fue más notable en la altura del brote. Es importante considerar la composición del medio de cultivo en cada etapa del proceso de micropropagación y la especie de Agave, con la finalidad de aumentar el volumen de producción de plantas con atributos que favorezcan la supervivencia en campo.

\section{LITERATURA CITADA}

Aguilar JD, Rodríguez DOJL (2018) Micropropagación y aclimatación de maguey pitzometl (Agave marmorata Roezl) en la Mixteca Poblana. Revista Colombiana de Biotecnología 10: 124-131.

Aureoles-Rodríguez F, Rodríguez-de la OJL, Legaria-Solano JP, Sahagún-Castellanos J, Peña-Ortega MG (2008) Propagación in vitro del 'Maguey bruto' (Agave inaequidens Koch), una especie amenazada de interés económico. Revista Chapingo. Serie horticultura 14: 263-269.

Barraza SS, Domínguez CPA, Montiel AE, Návar CJJ, Díaz VMA (2014) La producción de mezcal en el municipio de Durango, México. Ra Ximhai 10: 65-74. 
Candia-Acosta JA, Díaz-Vázquez MA, Torres HSI, Quiroz-Arratia JA, Domínguez-Calleros PA (2019) Germinación de semillas de Agave durangensis bajo diferentes coberturas en Durango, México. Revista Mexicana de Agroecosistemas 6: 18-27.

Chávez-Ortiz LI, Morales-Domínguez JF, Rodríguez-Sahagún A, Pérez-Molphe-Balch E (2021) In vitro propagation of Agave guiengola Gentry using semisolid medium and temporary immersion bioreactors. Phyton International Journal of Experimental Botany. DOI: 10.32604/phyton.2021.012862.

Domínguez RMS, González JML, Rosales GC, Quiñones VC, Delgadillo DLS, Mireles OSJ, Pérez MBE. (2008a) El cultivo in vitro como herramienta para el aprovechamiento, mejoramiento y conservación de especies del género Agave. Investigacion y Ciencia 16: 53-62.

Domínguez RMS, Alpuche SAG, Vasco MNL, Pérez MBE (2008b) Efecto de las citocininas en la propagacion in vitro de agaves mexicanos. Revista Fitotecnia Méxicana 31: 317-322.

Eguiarte FLE, González GA (2007) De genes y magueyes estudio y conservación de los recursos géneticos del tequila y el mezcal. Ciencias 87: 28-35.

García MAJ (2007) Los agaves de México. Ciencias 87: 14-23.

García HEJ, Mendez GSJ, Talavera MD (2010) El género Agave spp. en México: Principales usos de importancia socioeconómica y agroecológica. Revista Salud Pública y Nutrición, Edicion Especial. 5: 109-129.

González CG, Martínez GAE, Ortíz SIA, Gamero PEC y Valdéz OS (2020) Germinación in vitro de Agave victoriae-reginae T. Moone en medio de cultivo orgánico. Sapiens 1: 16-17.

Gónzalez CMP, Quintos EM (2006) Insectos asociados al Agave en el estado de Durango. VidSupra 1: 10-12.

Gónzalez DBM, Nuñez PG (2015) Micropropagación de Agave durangensis en un Sistema de Inmersion Temporal (SIT). Jóvenes en la Ciencia 1: 8-13.

Hernández VV, Orea LG, Gómez OS (2017) Efecto de la poda en plantas de agave mezcalero durante el trasplante a campo. VidSupra 9: 35-38.

Loera GHM, Corral RJJ, Montiel AE, Díaz VMA, Orona CI, Rodríguez TE, Ojeda MG, Torres HSI (2012) Factores ecológicos de una comunidad de Agave durangensis en la Sierra de Registrillo, Durango. México. Agrofaz 12: 81-88.

Loera GHM, Corral RJJ, Montiel AE, Solis MR, Chávez SJA, González CG (2018) Calidad de sitio para Agave durangensis Gentry en la Sierra de Registrillo, Durango. Revista Mexicana de Ciencias Agrícolas 9: 11711180.

Martínez-Ramírez S, Bautista-Sánchez G, Pedro-Santos EC, Guerrero-Cruz PD (2014) Crecimiento y contenido de clorofila del maguey mezcalero (Agave potatorum Zucc.) en policultivo con maíz y frijol. Revista Fitotecnia Mexicana 37: 297-304.

Miguel LME, Enríquez VJR, Velasco VVA, Villegas AY, Carrillo RJC (2014) Concentración de benciladenina, tipo y dosis de carbohidratos en el medio de cultivo para proliferación de brotes de Agave americana. Revista de la Facultad de Ciencias Agrarias 46: 97-107.

Murashige T, Skoog F (1962) A revised medium for rapid growth and bioassays with tobacco tissue culture. Physiologia Plantarum 15: 473-497.

Puente-Garza CA, Meza-Miranda C, Ochoa-Martínez D. García-Lara S (2017) Effect of in vitro drought stress on phenolic acids, flavonols, saponins, and antioxidant activity in Agave salmiana. Plant Physiology and Biochemistry 115: 400-407. 
Ramírez MRA, Borodanenko L, Pérez ML, Salas AMDHG, Nuñez P, Ochoa AN (2008) In vitro propagation of three Agave species used for liquor distillation and three for landscape. Plant Cell, Tissue and Organ Culture 94: 201-207.

Salazar-Mercado SA, Vega-Contreras NA (2017) Asymbiotic seed germination and in vitro propagation of Cattleya trianae Linden \& Reichb. f. (Orchidaceae). Acta Agronómica 66: 544-548.

Silos EH, González CN, Carrillo LA, Guevara LF, Valverde GME, Paredes LO (2007) Chemical composition and in vitro propagation of Agave salmiana "Gentry". Journal of Horticultural Science and Biotechnology 82: 355-359.

Valenzuela SKK, Juárez HRE, Cruz HA, Olalde PV, Valverde ME, Paredes LO (2006) Plant regeneration of Agave tequilana by indirect organogenesis. In Vitro Cellular \& Developmental Biology - Plant 42: 336-340.

Ying-Hua S, Yu-Bo L, Xian-Sheng Z (2011) Auxin-Cytokinin interaction regulates meristem development. Molecular Plant 4: 615-625. 